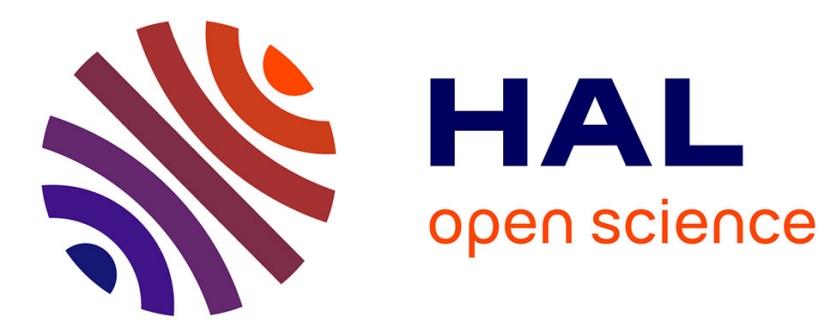

\title{
The spray-forming of thin wall shapes
}

G. Montavon, E. Roussel, C. Coddet, D. Cornu, J. de Monicault, J. Garcia, F. Pellerin, E. Fauvet, J. Huchin

\section{To cite this version:}

G. Montavon, E. Roussel, C. Coddet, D. Cornu, J. de Monicault, et al.. The spray-forming of thin wall shapes. Journal de Physique IV Proceedings, 1993, 03 (C7), pp.C7-277-C7-282. 10.1051/jp4:1993744 . jpa-00252162

\section{HAL Id: jpa-00252162 https://hal.science/jpa-00252162}

Submitted on 1 Jan 1993

HAL is a multi-disciplinary open access archive for the deposit and dissemination of scientific research documents, whether they are published or not. The documents may come from teaching and research institutions in France or abroad, or from public or private research centers.
L'archive ouverte pluridisciplinaire HAL, est destinée au dépôt et à la diffusion de documents scientifiques de niveau recherche, publiés ou non, émanant des établissements d'enseignement et de recherche français ou étrangers, des laboratoires publics ou privés. 


\title{
The spray-forming of thin wall shapes
}

\author{
G. MONTAVON, E. ROUSSEL, C. CODDET, D. CORNU*, J.M. DE MONICAULT*, \\ J.C. GARCIA ${ }^{* *}$, F. PELLERIN ${ }^{* *}$, E. FAUVET ${ }^{* * *}$ and J.P. HUCHIN HUt $^{* *}$ \\ LERMPS-IPSé, Institut Polytechnique de Sevenans, 90010 Belfort cedex, France \\ * Société Européenne de Propulsion, 27207 Vernon, France \\ ** TURBOMECA, 40220 Tarnos, France \\ ${ }^{* * *}$ SOCHATA, 86101 Chatellerault, France
}

\begin{abstract}
The works described in this paper are part of a general study concerning new methods for the realization of parts of turbo-engines and turbo-pumps; the results presented concern the superalloy INCONEL 625. At first are presented the metallographic structure of the deposits and secondly test-pieces developped in order to characterize their mechanical properties (i.e. NOL-Rings, tubes,...). The physical and mechanical properties of the sprayed and heat treated materials are then compared with those of forged and sintered materials. The performances of the sprayformed test-pieces was observed to be similar to the forged or sintered ones.
\end{abstract}

\section{INTRODUCTION}

The progress in the design of turbo engines in order to increase the efficiency, for example of the combustion chambers, and the availability of new materials with higher mechanical properties at high temperature increase drastically the machining costs by traditionnal processes.

The spray-forming appears then to have an important industrial potential in that it could permit to obtain thin complex parts with high mechanical properties at a moderate cost $(1,2)$.This technique consists to spray a more or less thick coating on a substrate of the given final shape and then to remove this substrate in order to obtain the part constitued only by the coating.

The aim of this paper is to present some results about the mechanical properties of such deposits obtained by plasma spraying under low pressure. Several materials were tested ; in this paper are presented the results obtained with the INCONEL 625, a well known alloy appreciated for its ductility and commonly used as armour plates.

A similar work dealing with VPS (vacuum plasma spray) forming of INCONEL 718 was recently published by Holmes et al (3). The results obtained showed excellent properties ; the fine grained, recrystallized material exhibited better mechanical properties than critical grade cast inconel 718 at cryogenic, room and elevated temperature.

\section{EXPERIMENTAL PROCEDURE}

The chemical composition of the IN 625 powder used in this work for the sprayforming is presented in the Table 1.

The powder grain size distribution determined by image analysis is presented in the table 2 . The figure 1 illustrates the spherical morphology of the atomized powder. 
Table 1 : Chemical analysis of the INCONEL 625

\begin{tabular}{|c|c|c|c|c|c|c|c|c|c|c|c|c|c|}
\hline \multicolumn{11}{|c|}{ weight \% } & \multicolumn{3}{|c|}{ ppm } \\
\hline $\mathrm{Ni}$ & $\mathrm{Cr}$ & Mo & Al & $\mathrm{Ti}$ & C & $\mathrm{Fe}$ & $\mathrm{Si}$ & $\mathrm{P}$ & $\mathrm{Nb}$ & $M n$ & $S$ & 02 & $\mathrm{~N} 2$ \\
\hline bal & 21.1 & 8.84 & 0.1 & 0.1 & 0.2 & 1.72 & 0.19 & 0.1 & 3.52 & 0.27 & 18 & 518 & 502 \\
\hline
\end{tabular}

Table 2: Powder size distribution

\begin{tabular}{|l|c|}
\hline SIZE & INCONEL 625 \\
\hline$[\mu \mathrm{m}]$ & {$[\%$ by volume] } \\
\hline $\mathrm{S}<16$ & 0.32 \\
\hline $16<\mathrm{S}<25$ & 38.82 \\
\hline $25<\mathrm{S}<40$ & 57.12 \\
\hline $40<\mathrm{S}<63$ & 3.75 \\
\hline
\end{tabular}

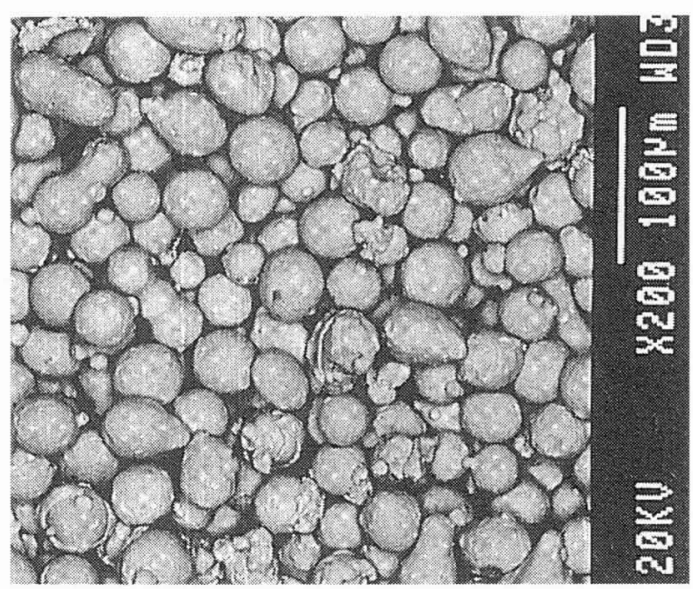

Figure 1: The INCONEL 625 powder

\section{EXPERIMENTAL CONDITIONS}

The material was sprayed under a low-pressure of argon with a Plasma-Technik F4 gun. The level of residual oxygen into the chamber was kept under $50 \mathrm{ppm}$ during the whole operation. Substrates of a cylindrical form with different compositions and dimensions were set in front of the torch, on a revolving axis. The gun was animated with a longitudinal motion, as shown schematically in the figure 2.

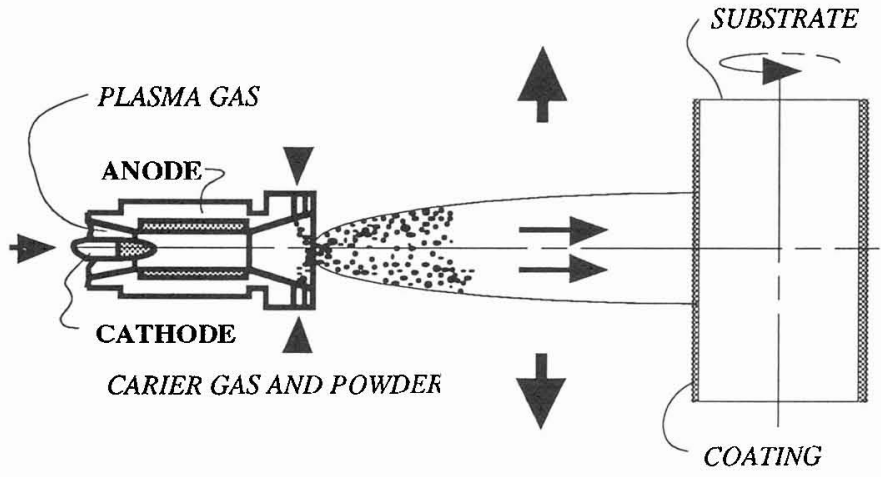

Figure 2: The torch-substrate configuration 
After spraying, the substrate was removed either by machining, chemical etching or other means depending upon its nature.

\section{METALLOGRAPHIC STRUCTURES}

The figure 3 shows the metallographic structure of the as-sprayed INCONEL 625 revealed by chemical etching. The structure appears very close to the conventionnal structure of the INCONEL 625 , unless the presence of some unmolten particles and macroporosities ( 0.05 to 0.1 vol \%).

In order to further homogenize the structure, heat-treatments were performed. The figure 4 presents the metallographic structure of the heat treated material.

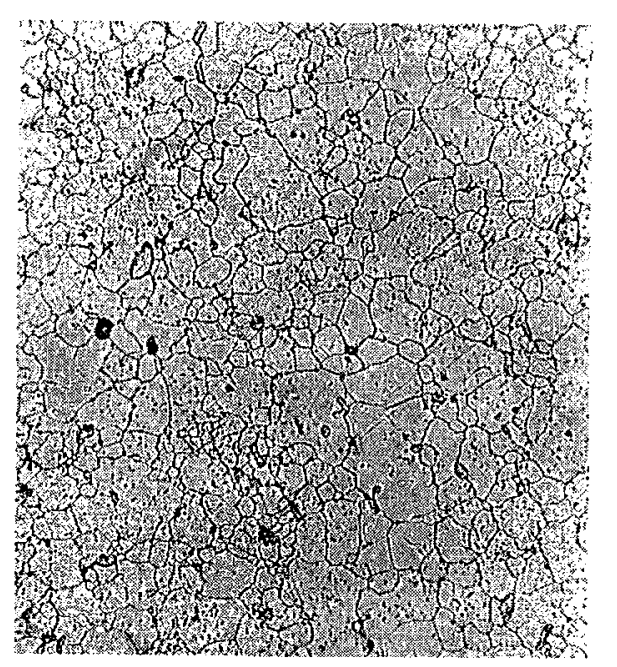

Figure 3: As-sprayed INCONEL 625 structure

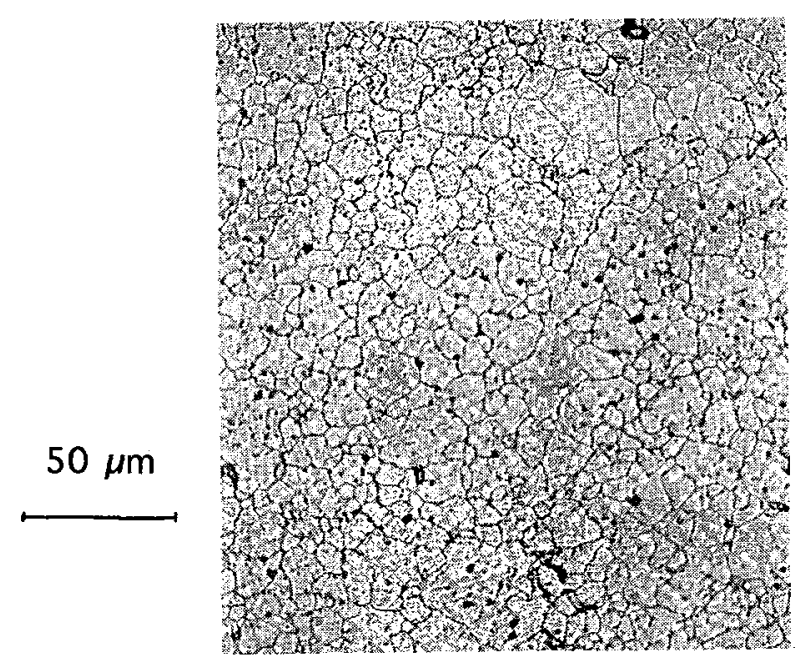

Fiqure 4: Sprayed INCONEL 625 structure after heat-treatment

\section{TENSILE TESTS}

Two differents ways were investigated to study the tensile properties of the deposited material. The first one was to use micro-tensile specimens milled in the thickness of the cylinders (figure 5) and the second one was to use NOL-ring specimens (figure 6) directly prepared by spraying. Mechanical properties were measured at different temperatures, from cryogenic $(20 \mathrm{~K})$, to room temperature and high temperatures $\left(350\right.$ and $\left.500^{\circ} \mathrm{C}\right)$.

The figure 7 shows the elongation (e), the yield strength (Y.S) and the ultimate tensile strength (U.T.S) versus temperature. Each value is the average of several tests performed in the same conditions (usually 3 tests). As in the previously mentionned case of the inconel 718 (3) the results appear to be very similar to those obtained with samples issued form a forging or a powder metallurgy route (figure 8 ) (4).

Furthermore, no significant difference was observed between the results obtained from the NOL-ring and from the micro-tensile specimens, in good correlation with the fine and homogeneous microstructure previously mentionned.

The fracture analysis (figure 9) indicates a ductile fracture, without any preferential propagation zone. 


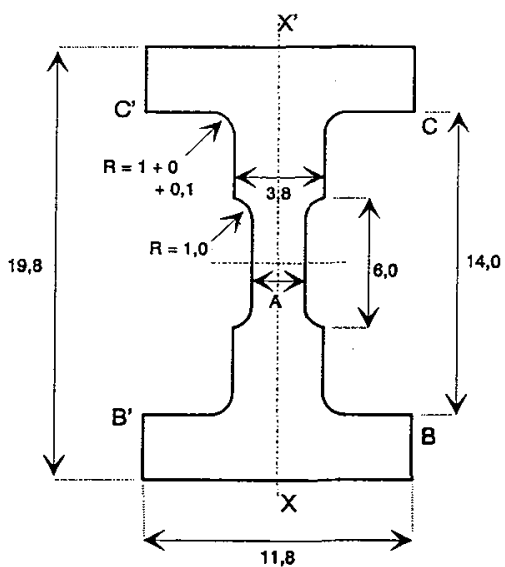

Figure 5 : Micro-tensile specimen

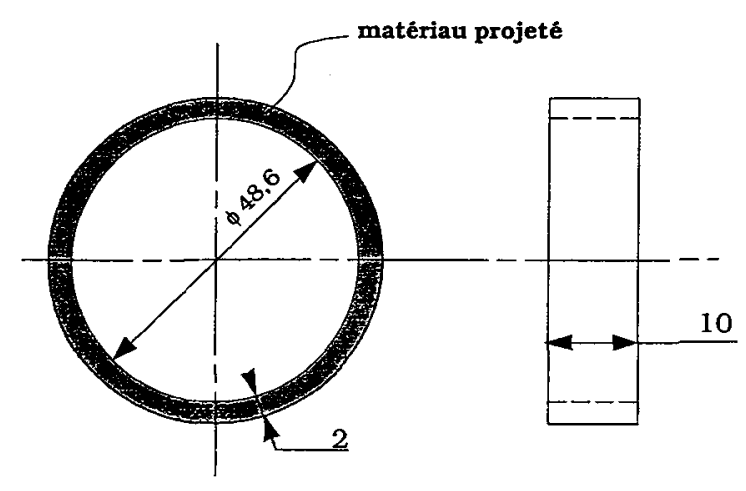

Figure 6 : The NOL-ring specimen

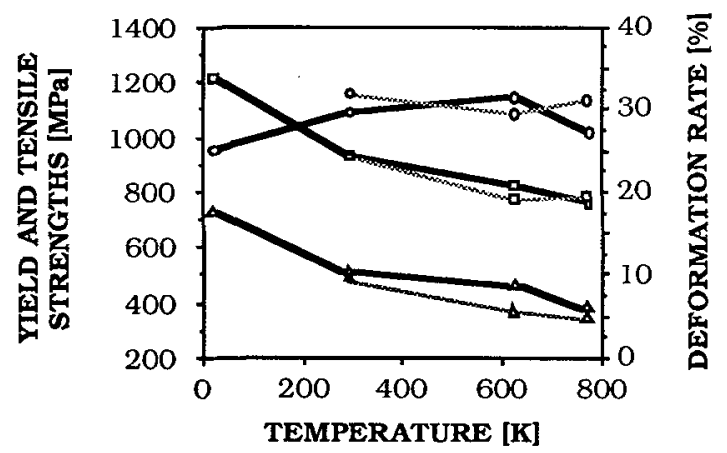

- NOL-Ring

...... Micro-tensile specimen

- Tensile strength (UTS)

$\Delta$ Yield strength (RO.2)

- Elongation (e)

Figure 7: Tensile properties of the sprayed and heat-treated INCONEL 625 versus temperature

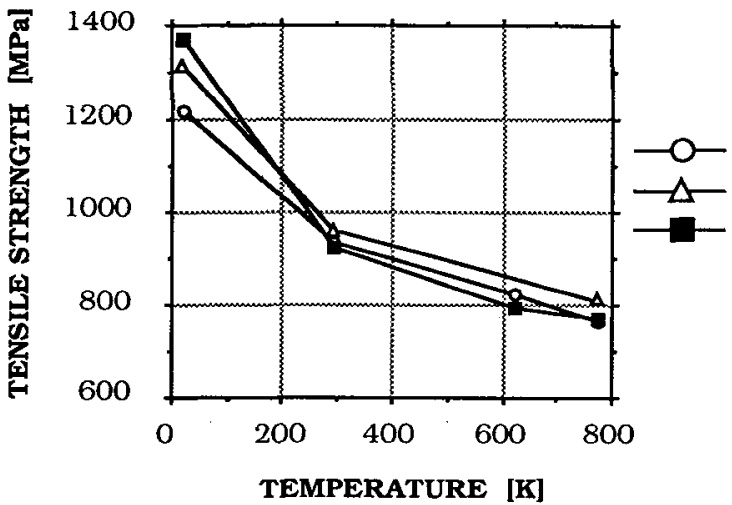

sprayed and heat-treated forged

powder metallurgy

Figure 8: Yield strength of the INCONEL 625 versus temperature, for different fabrication routes 


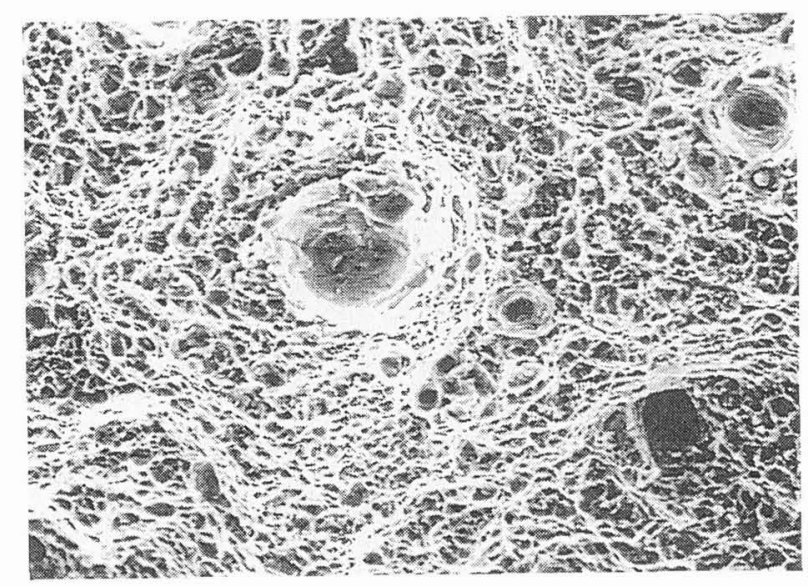

\section{LOW CYCLE FATIGUE (LCF) TESTS}

The LCF life-time was explored in the following conditions : temperature $500^{\circ} \mathrm{C}$, stress 600 and $650 \mathrm{MPa}$, frequency $10 \mathrm{~Hz}, \mathrm{R} 0.05$. The figure 10 shows the morphology of the specimens. Under these conditions the average number of cycles before failure is very high ( 1.200 .000 cycles for 600 $\mathrm{MPa}$ and 60000 cycles for $650 \mathrm{MPa}$ ) and largely exceed those obtained for powder metallurgy elaborated specimens ( 40.000 cycles). This excellent behaviour appears to be due to the appearance of a plastified zone. Further investigations are underway.

\section{ADHERENCE TESTS}

The spray-forming of thin parts may include the necessity to realize assemblies between a bulk material and a sprayed one, as illustrated schematically in the figure 11 . In order to assess the mechanical resistance of such assemblies, adherence tests were performed in order to determine the adherence of the sprayed material on a bulk material.

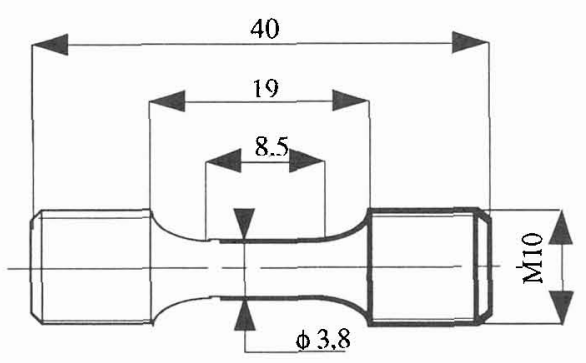

Figure 10: Morphology of the LCF specimens

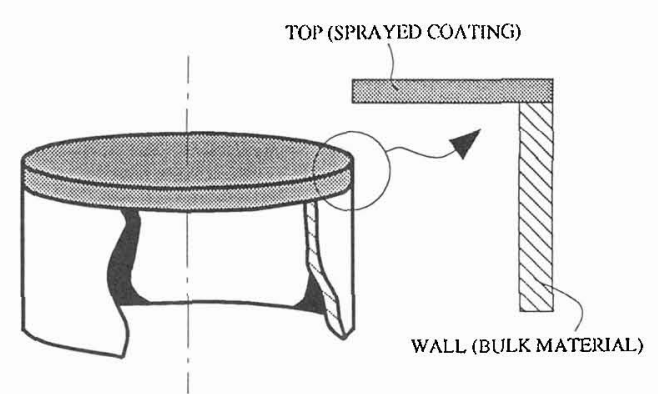

Figure 11: Schematic view of a composite asembly : bulk material and sprayed one

The configuration of the specimens is illustrated in the figure 12 . The base material used was HASTELLOY $X$. The surface preparation was made by sandblasting and furthermore using a negative transferred arc prior to the spraying. 


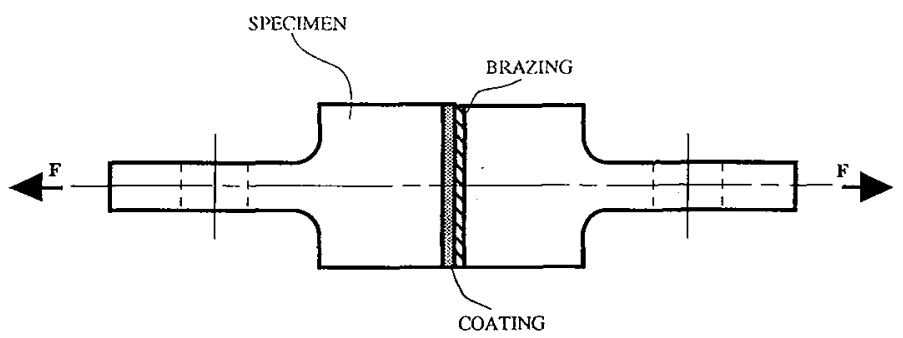

Figure 12 : Morphology of the adherence test specimens

After spraying the face of the first half test piece with $\mathbb{N} 625$ (up to a thickness of $1 \mathrm{~mm}$ ), the joining was obtained by brazing the two parts in such a way to ensure in the same time the heattreatment of the materials.

The first results obtained are presented in the table 4. In fact, they appear to have little signification, the rupture occuring the more frequently inside the brazing material. The choice of this brazing material is actually under discussion and further testing will be considered.

Table 4 : Results of the adherence tests (rupture inside the brazing material)

\begin{tabular}{|ccccc|}
\hline $\mathrm{T}, \mathrm{K}$ & 20 & 300 & 623 & 773 \\
\hline $\mathrm{Rm}, \mathrm{MPa}$ & 150 & 106 & 28 & 48
\end{tabular}

\section{CONCLUSION}

Thin and thick parts in INCONEL 625 were realized using plasma spray-forming under lowpressure.

The mechanical testings realized on machined specimens gave the following results:

i) the mechanical tensile properties of the sprayed material after heat-treatment are very similar to those obtained with the same bulk forged alloy.

ii) The specimens present excellent and outstanding LCF life-times. walls.

The following step will be the realization of structures containing bulk walls and thin sprayed

\section{REFERENCES}

[1] MOSS M., Acta Met., 16, 321 (1969)

[2] HUCHIN J.P., Proc. 1st Plasma-Technik Symposium Lucerne, Switzeriand, vol. 1 (1988)

[3] HOLMES R.R., BURNS D.H. and MC KECHNIE T.N. - Thermal Spray Research and applications, Proceedings, third Nat. Thermal Spray Conf., Long Beach, CA, USA, 20-25 May 1990 - Ed. T.M. BERNECKI, ASM.

[4] TURBOMECA, internal report. 